\title{
Foreign Experience of State Management of Raw Materials Industries and the Possibility of its Implementation in the Russian Federation in the Post-Covid Period
}

\author{
Dmitry Rodnyansky ${ }^{1, *}$, Ivan Makarov ${ }^{2}$, Evgeniya Korotayeva ${ }^{2}$, Vadim Kovrigin ${ }^{3}$, and \\ Vladislav Nazarenko ${ }^{2}$ \\ ${ }^{1}$ Kazan federal university, 420008 Kazan, Russia \\ ${ }^{2}$ The Russian Presidential Academy of National Economy and Public Administration, Lipetsk branch, \\ 398050 Lipetsk, Russia \\ ${ }^{3}$ Moscow Region State University, 141014 Mytischi, Russia
}

\begin{abstract}
In modern conditions, issues related to the effectiveness of the regulation of the oil industry by the state are becoming increasingly important. In January 2018, the World Economic Forum was held in Davos, which, in particular, noted the impact of the growth of protectionist trends in the global trade in hydrocarbons, and the impact of climate change on the planet on the export of hydrocarbons. As a result of the forum, the key ways of adjusting the policy of states in the relevant area were identified. At the same time, a significant number of states are already seeing the process of changing state regulation of the industry. In this article, the authors analyzed the systems of state regulation of the oil industry in different countries, and also gave assessments of the possibility of integrating new mechanisms into the system of sectoral management in Russia in the conditions of post-covid reality
\end{abstract}

\section{Introduction}

To characterize the state of the oil industry, as well as to forecast its development, indicators such as the level of production, reserves, the depth and volume of energy processing, as well as export / import indicators are used. At present, the oil industry is still the sphere on the development of which the revenue base of the federal budget largely depends. In the post-crisis period 2015-2016. there was a slight change in the ratio of the share of oil and gas budget revenues in comparison with other sources, but this was largely due to a decrease in world prices for oil and oil products. The energy dependence of the Russian economy is confirmed by such indicators as the ratio of total exports of goods and exports of hydrocarbons to GDP. In 2016, the first indicator was at the level of $21.9 \%$, and the second $-12 \%$, in 2017 the values of the indicators increased by $0.7 \%$ and $0.5 \%$, respectively, and amounted to $22.6 \%$ of GDP and $12.5 \%$.

\footnotetext{
*Corresponding author: ribnikoff@yandex.ru
} 
Table 1 shows the dynamics of revenues as a percentage of total exports and the total value of revenues to the federal budget from mining operations. As can be seen from the table, oil production, together with its refining, accounts for over $60 \%$ of all revenues (table 1).

Table 1. Share of extraction of minerals and oil refining in the total values of individual indicators, $\%$

\begin{tabular}{|c|c|c|c|c|c|}
\hline & $\mathbf{2 0 1 3}$ & $\mathbf{2 0 1 4}$ & $\mathbf{2 0 1 5}$ & $\mathbf{2 0 1 6}$ & $\mathbf{2 0 1 7}$ \\
\hline $\begin{array}{c}\text { \% of total } \\
\text { exports of } \\
\text { goods from }\end{array}$ & 71,7 & 70,9 & 64,3 & 60,2 & 62,4 \\
\hline $\begin{array}{c}\text { Balanced } \\
\text { financial } \\
\text { result,\% of } \\
\text { the total value }\end{array}$ & 33,4 & 48,2 & 37,0 & 24,4 & 33,1 \\
\hline
\end{tabular}

The increase in these indicators is also influenced by the outrunning growth of the extractive industry in the dynamics of industrial production. More than $70 \%$ of the integral growth in industrial production in 2017 was provided by the oil production and refining industries. (fig. 1)

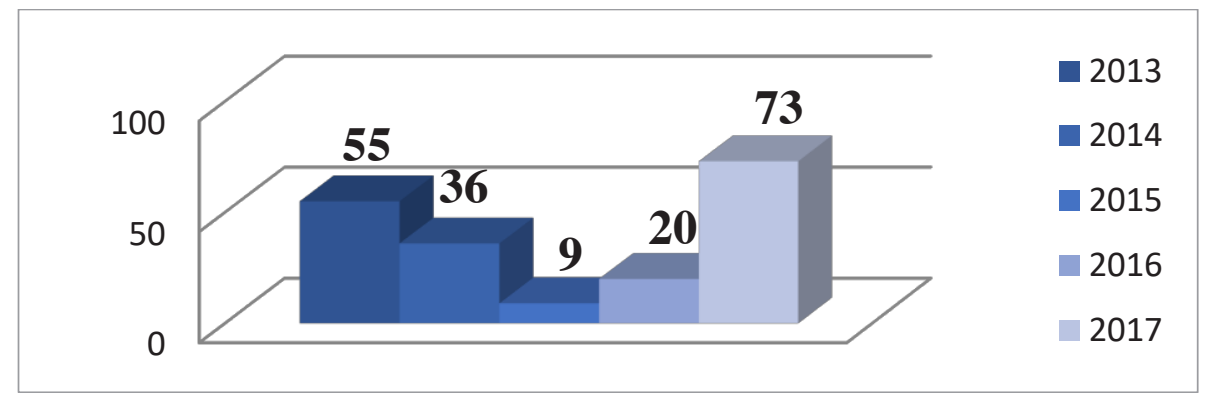

Fig. 1. Contribution of mining and oil refining to industrial production growth, 2013-2017,\%

\section{Materials and Methods}

Serious attention in the literature is given to the fuel and energy complex. Some authors analyze and calculate the contribution of the oil and gas industry to total GDP $[1,2,3]$. Other authors consider the oil industry as a driver of innovative development of the state $[5,6,7,8]$. Also in the literature there is a point of view that the oil industry is developing mainly in a number of resource regions and the basis for development is cluster initiative and cluster policy[9,10].

Exploring the specifics of the regulation of raw material industries by the state, it seems possible to point out the existence of the following models of state policy in the energy sector.

1. In states in which energy resources are abundant, the model of national monopoly prevails. The specifics of this model are as follows. The energy industry acts as a locomotive for the development of the country's economy. The state regards energy as a sphere, regulation and control in respect of which is completely the prerogative of the state. In this regard, there are tangible restrictions on entry into the industry for non-state players (both domestic and foreign).

2. Model of national competition. The formation of this model began in the eighties nineties of the last century. This period was characterized by energy reform in countries 
such as New Zealand, the United States of America, and a number of Western European countries.

Prior to this period, energy was a sphere of state dominance. In the eighties, with the spread of liberal approaches, there was a reduction in the participation of the state in various sectors of the economy. As a result of such reforms, significant positive dynamics was observed in the economy in the short term. At the same time, over a longer period, the implementation of the liberal strategy resulted in the development of crises in the energy sector. In the energy sector, it was necessary to carry out large projects, but it turned out to be difficult to attract investments in them. The consequence was a tangible shortage of energy resources, which, in turn, led to an increase in prices for these resources. Possible directions for solving this issue, tested in practice, are presented in the following form. In Chile, the United States of America, Argentina, government intervention in the energy sector has intensified, accompanied by a reduction in competition in the industry. In a number of other countries, general laws and standards for energy policy have been developed, which have acquired an integral character. On this basis, in a number of Scandinavian countries (Sweden, Norway, Finland, Denmark), a model of integration competition was formed, focused on the implementation of a single policy in the energy sector, the creation of a single energy market. There is significant government participation in these countries. At the same time, the role of coercive management and the use of administrative influences is comparatively smaller, with the predominance of creating conditions for market relations (in particular, through the development of regulatory frameworks for relevant relations).

It seems necessary to characterize the approaches of various states to the implementation of energy policy, the corresponding mechanisms of state participation in regulation with an assessment of the effectiveness of the functioning of the corresponding mechanisms.

\section{Results and discussions}

In the economy of the United States of America, the role of the oil and gas industry is very significant. At the same time, analyzing the size of the rent provided by this industry in the United States and other countries, it should be noted that it is significantly less than in Norway (82\%), Indonesia (up to 89\%), and the United Arab Emirates (up to 91\%). The amount of this rent is in the United States from $47 \%$ to $58 \%$. At the same time, private producers in the United States own nine-tenths of the country's raw materials, gas accounting for $82 \%$ of the total [11]. The entity that owns the land plot also has the property right to the mineral resources located on the site. A feature of the US energy industry is that the opportunities for foreign investors to participate in oil and gas production are strictly regulated and relatively insignificant. A similar approach is being pursued by the Middle East states of the Persian Gulf. In Qatar, Kuwait, Saudi Arabia, attracting foreign capital into the industry is excluded. The specificity of the United States is that here, in contrast to other countries of the world, private ownership of minerals is very significant.

Researchers believe that private ownership of minerals, the active participation of private companies in the extraction of raw materials determines the importance of the United States for the development of oil and gas production and processing on a global scale. Such an opinion seems to be justified, since a tangible increase in production in the oil and gas industry is due precisely to the progressive development of technologies, supported by investments of commercial organizations.

Along with entities such as private landowners, natural raw materials are owned by the US government, states, and tribal governments. The proportions of the distribution of 
ownership of raw materials in different states differ significantly. The United States Government's resource rights cover $39.8 \%$ of the nation's land spread across forty-eight states. One of the most significant in terms of hydrocarbon production is the state of Texas. At the same time, the ownership of the state (the US government and the state of Texas) on land plots with natural raw materials is insignificant here. In other states, which are of particular importance from the point of view of hydrocarbon production, the state's share in the ownership of natural resources is close to the share of private owners (for example, in Wyoming). Regardless of who owns the subsoil, oil and gas production is carried out mainly in accordance with the legal relationship of lease (leasing) of these natural resources. Direct ownership of natural resources by subsoil owners is of lesser importance. Contractual lease relations allow mining companies to reduce investment risks and the amount of required investments.

Considering the foreign experience, it seems important to analyze the Norwegian experience, since it has a rather significant practical interest. The similarity with the domestic oil and gas sector lies in the fact that this industry has the largest share in the structure of Norway's GDP. It is important that the state is the direct owner of all offshore oil and gas fields. Deoffshorization is not typical for the Norwegian model of oil industry management. Thus, all the capital that Norway receives from the export of resources does not go outside the country and continues to work to support national interests $[12,13]$.

Licensing of exploration and drilling operations is carried out within the Norwegian continental shelf. The process under consideration is quite significant and deserves special attention, since work in this direction is carried out not only by national companies, but also with the involvement of a fairly large number of foreign companies. The point is that foreign companies can be engaged in the development of deposits on the shelf only if they receive an appropriate permit from the Ministry of Energy and Oil. However, obtaining permission from the Ministry is the final stage, before proceeding to which the company must go through a licensing round and certain special procedures.

It is important to note that having a base that is not the most technologically advanced in the world, Norway is in 4th place in the international rating of natural gas exporters. Thanks to the formation of legal institutions that ensure the preservation of the interests and rights of investors, the attraction of large foreign investors to the national mining industry, the fair and indiscriminate granting of licenses for the extraction of minerals, as well as the provision of loans on favorable terms by Norwegian banks, the country manages to have one of the most high indicators of social protection of the population in the world.

Currently, the Norwegian government pays special attention to two areas: enhanced oil recovery and development of hard-to-recover reserves.

The experience with changes in taxation regimes for companies in the oil and gas sector is interesting. Norway uses a three-tier taxation system, which, according to many modern authors, is quite effective. The system lies in the fact that the tax rate depends on the size of the profit that the investor receives, which makes it possible to prevent conflicts between private companies and the state. At the same time, this flexibility in tax rates is a stimulating factor aimed at maximizing hydrocarbon recovery with available technologies.

The introduction of "green" initiatives is becoming a fairly relevant area, in addition to reforms aimed at changing tax systems. Thus, "green" initiatives provide for the introduction of special mechanisms and the development of regulatory aspects that are aimed at conserving natural resources.

A fairly active development of regulatory aspects, as well as a large number of innovations in the direction of improving the environmental situation, is noted in China. China's 13th Five-Year Social and Economic Development Plan has incorporated major changes in the above area. Thus, attracting investments in renewable energy sources, developing "clean" transport, increased control over hazardous environmental projects are 
the primary mechanisms of Chinese government regulation. Energy technologies such as wind and solar energy, as well as bioenergy, are planned for active development in order to implement the above areas $[14,15]$.

The experience of Italy can be quite interesting and useful. The New Energy Strategy has been approved in Italy. This strategy determines the growth of competitiveness due to the strengthening of energy state security. Let us note the main directions outlined in the framework of the considered strategy: training and retraining of labor resources to ensure the possibility of their activities with renewable energy sources, rationalization of land exploitation in the activities of energy enterprises, development of renewable energy sources, as well as optimization of the regulatory and legal framework in the direction of infrastructure construction energy.

The main target indicators by 2030 should be a reduction in Italy's dependence on imports of fuel and energy complex products by $22 \%$ (up to $54 \%$ ), an increase in the share of renewable energy sources to $55 \%$ versus $17.5 \%$ in 2015 , in particular, transport is expected to grow by $14.6 \%$.

\section{Conclusion}

Thus, the issue of revising the regulation measures for the fuel and energy complex by state authorities is now becoming increasingly important. Meanwhile, the needs of countries for energy resources grow as they develop, hence the growth rates of production. In this case, it has a negative effect on the environment, since emissions into the atmosphere and other consequences of energy consumption do not remain unnoticed.

Turning to foreign experience in the direction of state regulation of export-oriented industries makes it possible to generalize the implemented mechanisms of developed and developing countries. At the same time, to determine the acceptable options for achieving the growth of the state economy due to the use of the potential of the fuel and energy complex.

\section{References}

1. K. Aslani, Journal of Eurasian Studies, 6, 114 (2015)

2. A. Bykau, A. Ghodsi, H. Nezhadhossein, Financial markets, asset prices, international finance., 67 (2016)

3. G. Ravagnani, C. Lima, C. Barreto, F. Munerato, D. Schiozer., International oilfield chemistry symposium proceedings, 9 (2012)

4. L. Marques, D. Schiozer, International oilfield chemistry symposium proceedings, 14 (2014)

5. M. Thurber, D. Hults, P. Heller, Energy Policy, 5336 (2011)

6. M. Antolin, J. Cendrero, Energy Policy ,707 (2013)

7. T. Fitzerald, R. Rucker, OPEC Energy Review, 40 ( 2016)

8. I. Stepanov, HSE Economic Journal, 311 (2019)

9. D. Rodnyansky, R. Abramov, M. Repin, E. Nekrasova, International Journal of Supply Chain Management., 929 (2019)

10. The Cluster Policies Whitebook, (2004)

11. T. Fitzerald, R. Rucker, OPEC Energy Review, 41( 2016)

12. R. Dahl, S. Lorentzen, A. Oglend, P. Osmundsen, Energy Policy., 68 (2017) 
13. T. Hunter, The Extractive Industries and Society, 48 (2014)

14. N. Leung, M. Cheng, China J. of Accounting Research, 1 (2013)

15. L. Liu, N. Subramaniam, J. Account Public Policy., 161 (2013) 